\title{
Simulation of transcontinental wind and solar PV generation time series
}

Nuño Martinez, Edgar; Maule, Petr; Hahmann, Andrea N.; Cutululis, Nicolaos Antonio; Sørensen, Poul Ejnar; Karagali, loanna

Published in:

Renewable Energy

Link to article, DOI:

10.1016/j.renene.2017.11.039

Publication date:

2018

Document Version

Peer reviewed version

Link back to DTU Orbit

Citation (APA):

Nuño Martinez, E., Maule, P., Hahmann, A. N., Cutululis, N. A., Sørensen, P. E., \& Karagali, I. (2018).

Simulation of transcontinental wind and solar PV generation time series. Renewable Energy, 118, 425-436.

https://doi.org/10.1016/j.renene.2017.11.039

\section{General rights}

Copyright and moral rights for the publications made accessible in the public portal are retained by the authors and/or other copyright owners and it is a condition of accessing publications that users recognise and abide by the legal requirements associated with these rights.

- Users may download and print one copy of any publication from the public portal for the purpose of private study or research.

- You may not further distribute the material or use it for any profit-making activity or commercial gain

- You may freely distribute the URL identifying the publication in the public portal

If you believe that this document breaches copyright please contact us providing details, and we will remove access to the work immediately and investigate your claim 


\section{Accepted Manuscript}

Simulation of transcontinental wind and solar PV generation time series

Edgar Nuño, Petr Maule, Andrea Hahmann, Nicolaos Cutululis, Poul Sørensen, loanna Karagali

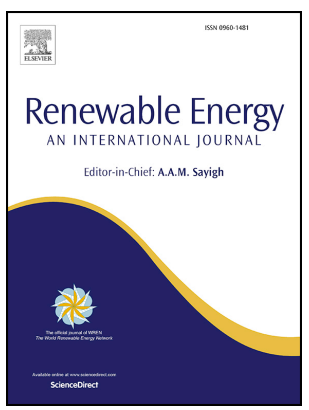

PII: $\quad$ S0960-1481(17)31140-0

DOI: $\quad$ 10.1016/j.renene.2017.11.039

Reference: RENE 9441

To appear in: Renewable Energy

Received Date: 28 June 2017

Revised Date: 4 November 2017

Accepted Date: 13 November 2017

Please cite this article as: Nuño E, Maule P, Hahmann A, Cutululis N, Sørensen P, Karagali I, Simulation of transcontinental wind and solar PV generation time series, Renewable Energy (2017), doi: 10.1016/ j.renene.2017.11.039.

This is a PDF file of an unedited manuscript that has been accepted for publication. As a service to our customers we are providing this early version of the manuscript. The manuscript will undergo copyediting, typesetting, and review of the resulting proof before it is published in its final form. Please note that during the production process errors may be discovered which could affect the content, and all legal disclaimers that apply to the journal pertain. 


\title{
Simulation of transcontinental wind and solar PV generation time series
}

\author{
Edgar Nuño*, Petr Maule, Andrea Hahmann, Nicolaos Cutululis, \\ Poul Sørensen and Ioanna Karagali \\ Department of Wind Energy, Technical University of Denmark, \\ Roskilde
}

\begin{abstract}
The deployment of Renewable Energy Sources (RES) is driving modern power systems towards a fundamental green transition. In this regard, there is a need to develop models to accurately capture the variability of wind and solar photovoltaic $(\mathrm{PV})$ power, at different geographical and temporal scales. This paper presents a general methodology based on meteorological reanalysis techniques allowing to simulate aggregated RES time series over large geographical areas. It also introduces a novel PV conversion approach based on aggregated power curves in order to capture the uncertainty associated to the technical characteristics of individual installations spread across large regions. The proposed methodology is validated using actual power data in Europe and can be applied to represent intermittent generation in network development plans, reliability and market studies, as well as operational guidelines.
\end{abstract}

Keywords: Large-scale integration, Renewable energy sources,

Solar power, Wind power

\section{Introduction}

Renewable energy sources (RES) have experienced a rapid growth over the last decades. Consequently, solar and wind generation already cover a significant amount of the electrical demand in several countries around the world.

*Corresponding author: ednu@dtu.dk 
5 Furthermore, the reduction in the levelized cost of energy (LCOE) following the technology readiness level together with a climate of increasing environmental concerns clearly suggest that green energy will play a much bigger role in the future. RES have a limited predictability from the power system perspective, which represents a major difference compared to conventional $\mathrm{CO}_{2}$ based generation technologies. Policy makers, system operators and planners have raised concerns that higher penetration of RES might significantly affect the operation of future power systems; justifying the need to properly address intermittent generation in network development plans, reliability and market studies, as well as operational guidelines. Both wind and solar generation are driven by a common meteorological process and consequently their temporal and spatial inter-relations at different time scales need to be captured. In addition, it is important to see renewable generation as a global phenomena rather than a country-specific issue. For example, the degree of interconnection in Europe has significantly increased over the last decades towards achieving a common European electricity market. Moreover, the role of organizations such as the European Network of Transmission System Operators (ENTSO-E) and the Council of European Energy Regulators (CEER) has bettered the cooperation between individual Transmission System Operators (TSOs) and Market Operators (MOs). Hence, from a system planning perspective, Europe can be 25 seen as a single transcontinental power system.

The long-term planning of the transcontinental European power system, as in the Ten Years Network Development Plan published biannual by ENTSO$E$, requires data about the expected hourly energy production from renewable sources, necessary to estimate the expected cross-border flows. In this regard, there is an increasing interest to study the characteristics of renewable energy production over large areas and to develop models to reproduce these properties. Both spatial and temporal characteristics of wind generation were studied in [1] and 2], using historical data from the United States and Europe respec35 tively. Similarly, [3] analysed the correlation between wind and solar generation 
in Sweden. In addition, meteorological reanalysis techniques have proven to be a powerful tool to generate plausible past states of the atmosphere across large geographical areas over time. This meteorological information can be then used to perform country-wise simulations of wind power generation [4, 5], solar

40 generation [6] as well as both wind and solar power across Europe [7]. This work aims at presenting a detailed methodology to generate hourly time series of aggregated wind and solar at the country level. The main contributions of the paper are twofold. Firstly to present a novel data-driven solar PV conversion model based on the concept of aggregated power curves. Secondly, to apply it to generate joint wind and solar time series over a large transcontinental system. The paper is organized as follows. Section 2 describes the meteorological model which lays the groundwork for this paper. The methods used to transform these weather variables into electrical power are detailed in section 3 Input data are briefly summarized in section 4 and validation results are presented in section 5

50 Finally, section 6 summarizes the main findings of this work, along with some concluding remarks.

\section{The meteorological model}

Wind and solar generation mainly depend on the current wind speeds and solar radiation. Therefore, the first step in our model is to derive the weather conditions at mesoscale level. The time series of meteorological input fields were produced by dynamical downscaling, which is a method for obtaining high-resolution climate or climate change information from relatively coarseresolution global general circulation models or reanalysis. We used the mesoscale downscaling method presented in [8], 9] to generate time series of wind speed and other meteorological fields for Europe and Northern Africa. It uses the Weather Research and Forecasting (WRF) [10] model, an open-source widely used mesoscale modelling system. The details of the simulation are given in Table 1 whereas Table 2 gives details of the time series. The simulations performed here were similar to those used in the generation of the Numerical Wind Atlas 
of South Africa [11]. The WRF model was integrated within three domains shown in Figure 1, namely North, South Europe and North Africa. Each was configured with an outer and inner domain of $30 \mathrm{~km}$ and $10 \mathrm{~km}$ grid spacing. A similar method for deriving time series was used and verified in [8] and 9]. Ini-

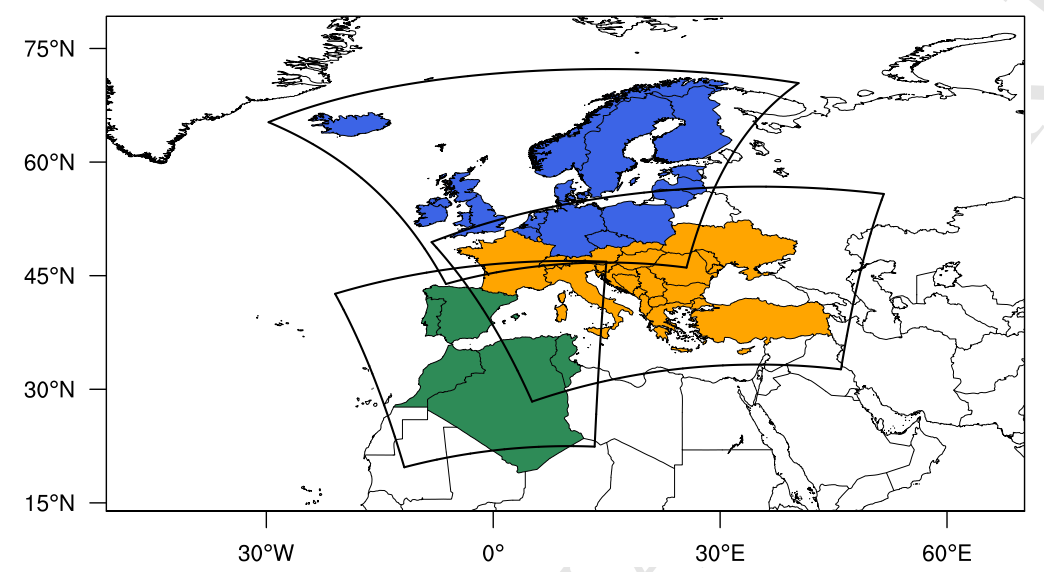

Figure 1: Model domain configuration used in the WRF model simulations. Countries in blue use WRF data from the Northern domain. Countries in yellow and green use WRF data from the Southern domain.

tial, boundary and grids for nudging the WRF simulations are supplied by the ERA Interim Reanalysis 12 at approximately $0.7^{\circ} \times 0.7^{\circ}$ latitude vs. longitude grid spacing. We used a three-dimensional analysis nudging method, whereby the atmospheric model was nudged towards time- and space-interpolated analyses using a point-by-point relaxation term. Sea surface temperatures (SSTs) at a horizontal resolution of $0.25^{\circ} \times 0.25^{\circ}$ latitude vs. longitude [13] was also 75 used in the simulations. 
Table 1: Model characteristics

\begin{tabular}{|c|c|}
\hline Model Setup & \\
\hline WRF version & 3.7 .1 \\
\hline Northern domain & Polar stereographic projection \\
\hline Southern domain & Lambert conformal projection \\
\hline Vertical levels & 41 with model top at $50 \mathrm{hPa}$ \\
\hline Land classification & blended CORINE (Europe) and MODIS \\
\hline Simulation Setup & \\
\hline $\begin{array}{l}\text { Initial boundary } \\
\text { conditions \& } \\
\text { nudging }\end{array}$ & ERA-Interim Reanalysis \\
\hline Runs initialization & 00:00 UTC every 10 days \\
\hline Integration & 11 days. First 24 hours disregarded \\
\hline Updates & NCEP OISST \& sea-ice (daily) \\
\hline $\begin{array}{l}\text { One-way nested } \\
\text { domains }\end{array}$ & 5-grid point nudging zone \\
\hline $\begin{array}{l}\text { Spectral grid } \\
\text { nudging }\end{array}$ & $\begin{array}{r}\text { above the planetary boundary layer } \\
\text { (PBL) }\end{array}$ \\
\hline
\end{tabular}

The time series of meteorological fields were derived directly from the output of the WRF model simulations. The various data are further described in Table 2. To obtain the values at the desired height (i.e. $100 \mathrm{~m}$ ), wind speeds were interpolated from neighbouring model levels using a logarithmic weighing as described in [9. We used the version 3.7.1 of the WRF model (released on August 2015) to take advantage of new advances in parametrizations for radiation and cloud processes. Also, this latest version includes updated output fields for direct and diffuse irradiance and cloud fraction. We selected a RRTMG scheme for long-wave and short-wave radiation and modelled precipitation using a WRF Single-Moment 5-class scheme using the Kain-Fritsch cumulus parametrization. The Planetary Boundary Layer (PBL) was parametrized using a Mellor-Yamada-Jancic scheme [14. In addition, we selected a simple diffusion model (option 1) with 2D deformation (option 4), $6^{\text {th }}$ order positive definite 
numerical diffusion (option 2) and vertical damping. Both moisture and scalars were parametrized using the positive definite advection scheme. The physical parametrizations were chosen according to the sensitivity experiments in 9] and other (unpublished) wind atlas reports. The choices related to the solar radiation calculations were based on Jimenez et al (2015) [15].

Table 2: Meteorological data summary

\begin{tabular}{|c|c|c|}
\hline Variable & Units & Height (AGL) \\
\hline Wind speed ${ }^{1,3}$ & $\mathrm{~m} / \mathrm{s}$ & $100 \mathrm{~m}$ \\
\hline Air temperature ${ }^{1,3}$ & ${ }^{\circ} \mathrm{C}$ & $2 \mathrm{~m}$ \\
\hline City air temperature ${ }^{2,3}$ & ${ }^{\circ} \mathrm{C}$ & \\
\hline Population weighted temperature ${ }^{1,4}$ & ${ }^{\circ} \mathrm{C}$ & $2 \mathrm{~m}$ \\
\hline Global horizontal irradiance ${ }^{1,3}$ & $\mathrm{~W} / \mathrm{m}^{2}$ & Surface \\
\hline Average cloud cover ${ }^{1,3,5}$ & Okta & Medium and low clouds \\
\hline
\end{tabular}

Notes: node averaged ${ }^{1}$, closest grid point ${ }^{2}$, hourly averaged ${ }^{3}$, population density used for area averaged ${ }^{4}$, maximum random overlap ${ }^{5}$

Simulated WRF wind speeds have been validated for different locations in Scandinavia. A summary can be found in reference 9]. Furthermore, we conducted some initial comparisons between the solar radiation simulations and different measurement stations in Germany. A more detailed report has been attached as additional material to the paper. The WRF runs were used as inputs for calculating the onshore, offshore wind and PV load factors. These are further described in what follows.

\section{Power conversion models}

The environmental variables derived from the meteorological model had to be translated into electrical power. We aimed at simulating the annual and seasonal production for each technology, which essentially required matching the real capacity factor. For a given technology $k$, the capacity factor for the year $i$ can be defined as the ratio between the actual energy produced and the 
maximum possible output, corresponding to all plants generating their nominal power:

$$
C_{i, k}=\frac{1}{8760} \sum_{t=1}^{8760} \frac{E_{t, i, k}}{P_{t, i, k}}
$$

where $E_{t, i, k}$ is the power produced by technology $k$ at hour $t$ of year $i$ and $P_{t, i, k}$ corresponds to the total nominal installed capacity of technology $k$ at hour $t$ of year $i$. In practice, it is not always possible to monitor the hourly installed capacity for each specific technology. Thus, eq. (1) can be approximated as:

$$
C_{i, k}=\frac{\sum E_{t, i, k}}{\left|P_{i, k}-P_{i-1, k}\right| \cdot \cdot 0.5 \cdot 8760}
$$

where $P_{i, k}$ is the total nominal capacity of technology $k$ at the end of year $i$ and $P_{i-1, k}$ is the nominal capacity at the end of the previous year i.e. $i-1$. The overall time series generation process is presented in Figure 2.

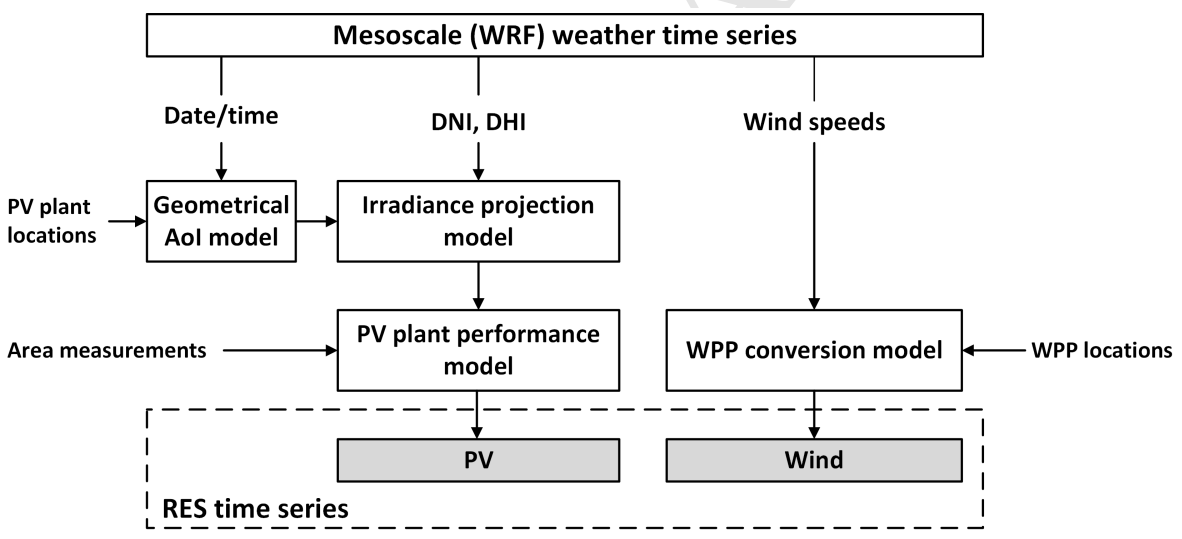

Figure 2: Schematic diagram for the PV power and wind power time series generator. WPP stands for wind power plant and WRF for the weather research and forecasting model. The underlying meteorological phenomena are captured using a single model, which guarantees that the true correlations between generated wind and solar power are preserved.

\subsection{Wind to power}

The wind to power conversion model is based on a power curve, which is a static representation of the wind turbine electric power output as a function of the hub height wind speed [16]. With such a curve, turbine power output 
and energy production can be calculated without detailed knowledge of turbine well as historical aggregated PV generation data. The main objective was to define a reference panel for each area/country, with a fixed optimal orientation 
and inclination matching historical PV power time series. As an initial step, the a combination of panel orientation and inclination.

Even though each possible scenario translates into a different effective irradiance, the measured power is unique. This fact explains the various shapes 

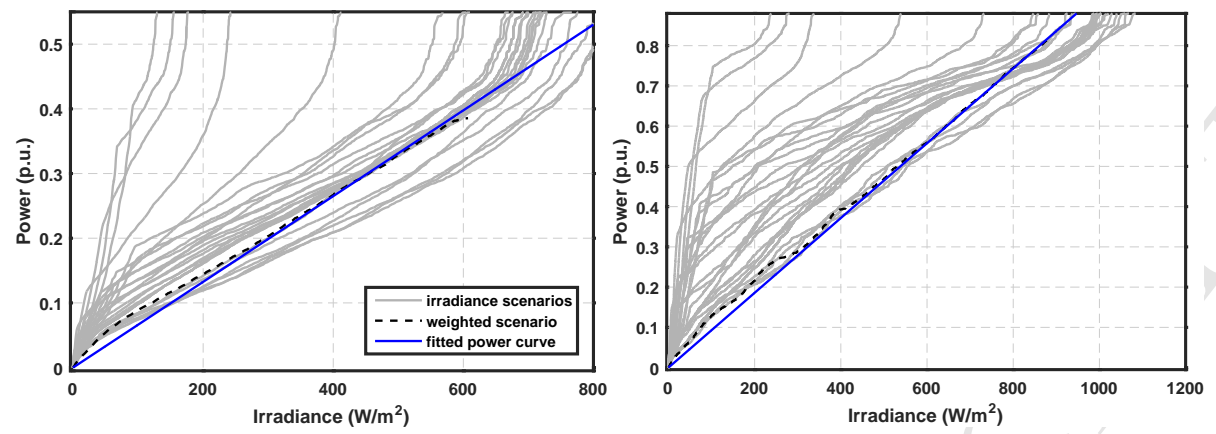

Figure 3: Aggregated power curves (in blue) for two regions: Bremen and Lower Saxony, Germany (left) and Murcia, Spain (right). The grey lines correspond to the initial cloud of empirical power curves matching the quantiles of the measurements and the quantiles of the effective irradiance associated to each combination of tilt and azimuth angles. The weighted scenario is represented by a black dashed line and the fit corresponding to the (true) final power curve is depicted in blue.

obtained. In general, the true power curve describing the relationship between the (true) averaged effective irradiation and the total power output, $\mathcal{P}_{\text {true }}$ (represented by a dashed black line in Figure 3), would correspond to a combination of the $N$ different scenario power curves:

$$
\mathcal{P}_{\text {true }}=\sum_{i=1}^{N} \omega_{i} \cdot p_{i}, \quad \forall p \in \mathcal{P}, \forall \omega \in \mathcal{W}
$$

where $p_{i}$ is the power curve and weight associated to the specific $\mathrm{i}-t h$ scenario and $\mathcal{W}$ is a set of weighting factors. We performed an ordinary least squares regression on the estimated power for each scenario against the actual power measurements in order to calculate the set of weights $\mathcal{W}$ that minimized the difference to actual annual capacity factor. We did not consider an intercept term and constrained all coefficients to be non-negative. The empirical weighting factors can be seen as an estimate of the mean inclination and orientation of the panels inside a given area and their interpretation is straightforward: the higher the weight for a specific combination, the closer it would be to the real distribution of orientations and inclinations of the panels. For example, Table 
Table 3: Scenario weights for two European regions

\begin{tabular}{lcc}
\hline Scenario & Bremen \& L. Saxony & Murcia \\
\hline South $-30^{\circ}$ & 0.2715 & 0.8523 \\
South $-45^{\circ}$ & 0.4267 & - \\
North $-45^{\circ}$ & - & 0.0097 \\
West $-90^{\circ}$ & 0.0491 & 0.0472 \\
North $-90^{\circ}$ & 0.2153 & 0.0912 \\
East $-90^{\circ}$ & 0.0857 & 0.0804 \\
\hline
\end{tabular}

3 summarizes the weights corresponding to the different scenarios presented in Figure 3. Once the set of weights $\omega_{i} \in \mathcal{W}$ has been defined, it is possible to reproduce $\mathcal{P}_{\text {true }}$ which can be fitted using a linear function i.e. blue line in Figure 3. This linearity assumption relies on the intrinsic radiation-to-power conversion mechanism. Besides, we found that a high-order polynomial fit did not bring any significant advantage. The module temperature is a variable that might affect this idea relationship. However, empirical evidence showed that at this level of spatial aggregation, all the non-ideal effects are captured by the slope of the curve. Besides, using a linear model facilitates the aggregation of regional power curves, since the different slopes can be weighted according to their installed capacity. The process can be summarized as follows:

Step 1 - Combine each PV location to the lowest level of aggregation and aggregate them to the closest meteorological point.

Step 2 - Calculate the empirical power curves corresponding to each tilt-azimuth combination and obtain their linear approximations $p \in \mathcal{P}$.

Step 3 - Apply the power curves from (2) to simulate the annual PV power for each scenario.

Step 4 - Obtain the set of weighting factors $\mathcal{W}$ by performing a linear regression on the power scenarios (3) in order to minimize the error on the actual 
energy yield. Constrained the parameters to be non-negative:

i.e. $\omega>0 \forall, \omega \in \mathcal{W}$.

Step 5 - Use the set of weights obtained in (4) to calculate the true averaged effective irradiance for that region.

Step 6 - Derive the empirical true power curve by matching the quantiles of the effective irradiance from (5) to the quantiles of the measurements and approximate it using a linear function $\mathcal{P}_{\text {true }}$.

The spatial resolution of the model is limited by the available PV power measurements. When regional data are available, an average aggregated power curve per country can be obtained by weighting each regional power curve by its installed capacity.

\section{Input data}

We used different inputs to the model besides the meteorological reanalysis data detailed in Section 2. We selected 2014 as a representative year to characterize the spatial distribution of the wind generation fleet combining the information from DTU Wind's internal database, data from www . thewindpower . net and annual statistics from the European Wind Energy Association (EWEA). The approximate distribution of PV installations was derived based on the European Photovoltaic Industry Association (EPIA) statistics, national energy agencies and regulators e.g. Bundesnetzagentur (Germany), Gestore dei Servizi Energetici, GSE (Italy), Comisión Nacional de los Mercados y la Competencia, CNMC (Spain), Commission wallonne pour l'Energie (CWaPE) and Vlaamse Regulator van de Elektriciteits- en Gasmarkt VREG, (Belgium). The calibration and validation of the model outputs was performed combining hourly time series gathered from ENTSO-E's transparency platform and Key Electricity Figures as well as data publicly available from the individual TSOs. We considered 39 different regional power curves, corresponding the NUTS2 [22] aggregation 
level in Spain and Belgium, the market node level in Italy and a combination of NUTS2 and TSO division in Germany.

\section{Results and validation}

The proposed model has two main objectives. First, to reproduce the inherent variability of wind and solar generation. It corresponds to daily and seasonal patterns, captured by the meteorological model. Additionally, the method has to match the actual capacity factors per region, defined as the percentage of energy produced in a given area with respect to the maximum possible i.e. running at nominal capacity all the year. The choice of both wind and solar power curves will largely affect this feature. In this work, we applied generic aggregated wind power curves to model the wind-to-power conversion. Furthermore, we used all the empirical data available prior to 2015 to estimate the solar scenario weights and the aggregated PV power curves. For the solar case, we left the measurements from 2015 for validation. Note that these data correspond to up-scaled power time series of PV generation aggregated per region and wind power time series per country. There is no public information available regarding the aggregation methodology, although it is a relatively common practice among European TSOs, specially when not all the individual facilities are monitored e.g. roof-mounted solar PV. We focused on four main features during the validation of the simulated time series: (a) seasonal daily patterns, (b) interannual variation, (c) error distribution as well as the distributional properties, autocorrelation functions. For comparison reasons, all the results through the paper are normalized to each area's installed capacity. Hence, 1 indicates the corresponding nominal power production.

\subsection{Wind power}

We applied two different wind power curves corresponding to the two most common wind turbine technologies i.e. stall and pitch-controlled. The seasonal and diurnal patterns of the wind load factors were calculated and compared for 

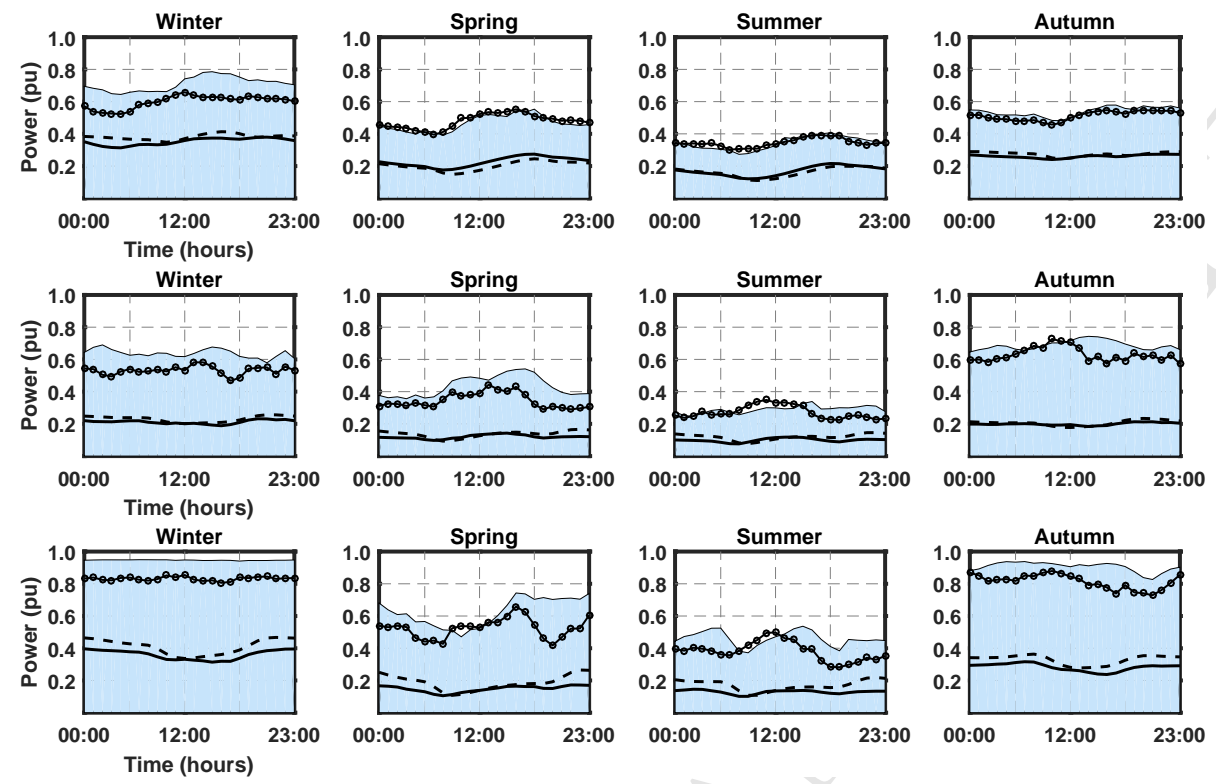

Figure 4: Wind power seasonal average daily production in Spain (top row), Germany (middle row) and Belgium (bottom row) in 2014. The full and dashed lines correspond to the historical and simulated mean production respectively. The dotted line represents the $95^{\text {th }}$ historical percentile and the shaded blue area the $95^{\text {th }}$ simulated percentile

several countries. In the following, the detailed results for Spain, Germany and Belgium corresponding to three different climatic areas are presented. Figure 4 illustrates the daily evolution of the average wind production per season for each country. On average, the model (dashed black line) was able to capture the behaviour of the actual wind production (black line) quite accurately. As expected there was generally a clear difference in production between summer and winter months, which was also reproduced by the model. We also looked at extreme events, represented by the $95^{\text {th }}$ quantile i.e. the value higher than $95 \%$ of the data. Despite the fact that the model replicated the production during spring, summer and autumn in the Spanish case quite accurately, the simulated extreme results (blue area) tended to be higher than the historical values (dotted line). This was expected since simulations are able to capture the available wind resource and even though wind power plant (WPP) reliability 

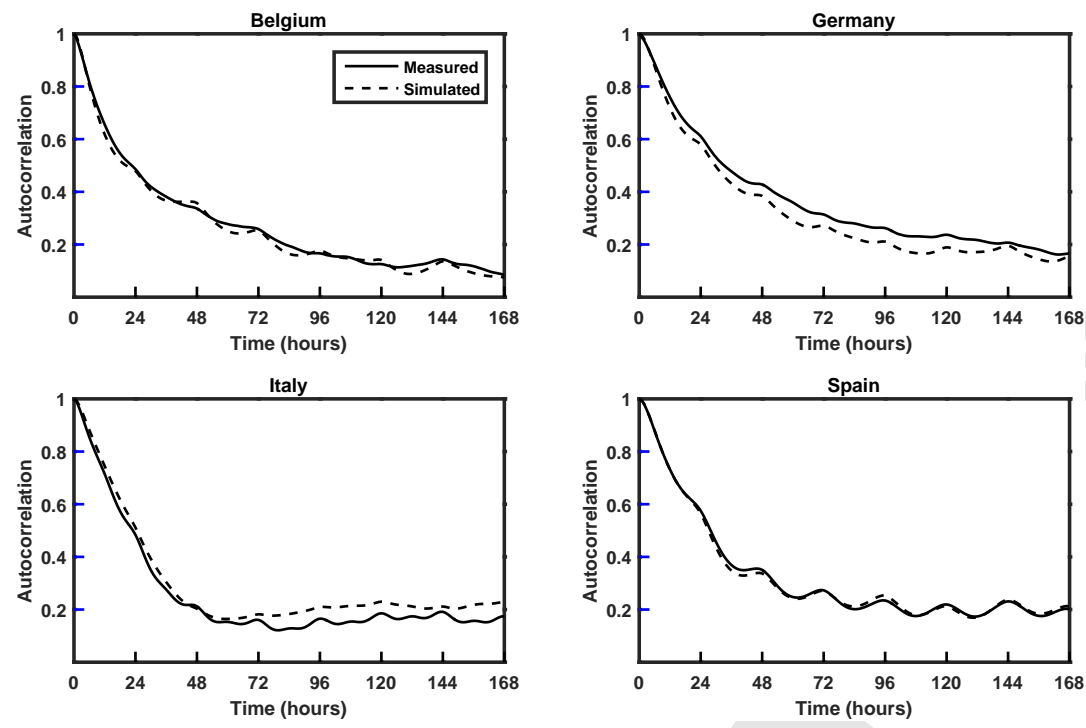

Figure 5: Measured and simulated autocorrelation functions of wind power generation.

was considered, the specific curtailment strategies followed by the different TSOs were not included in the model. The impact of the installed capacity distribution can be clearly observed. For example, Belgium has a much higher capacity factor during winter and autumn compared to Spain and Germany since generators are more geographically clustered. Furthermore, we did not observe any systematic bias in the error throughout the day. Figure 5 shows the temporal structure of simulated and measured wind power time series. It can be seen that the model successfully captured the high persistence observed in the actual data.

\subsection{Solar power}

In this section, the validation of the simulated solar generation for three areas in Spain, Germany and Belgium in 2015 are presented. Figure 6 shows both measured and simulated seasonal daily profiles of solar generation. The model clearly captured the PV power variability across the year. Moreover, it was able to simulate extreme events accurately for all the seasons in Murcia and Bremen and Lower Saxony, except for winter. As opposed to the simulated wind series, the model under estimated the $95^{\text {th }}$ percentile in Liege. Albeit no data 


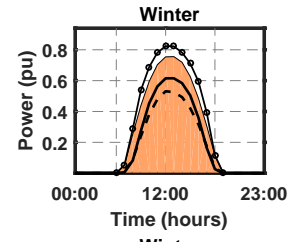

Winter

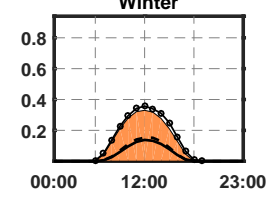

Winter

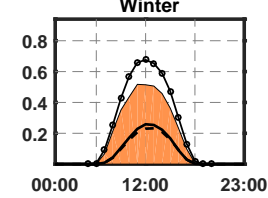

Spring

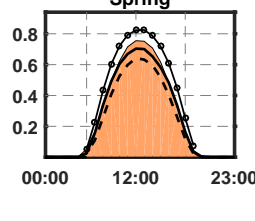

Spring

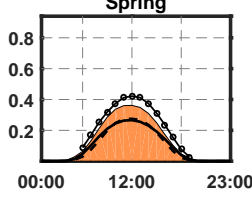

Spring

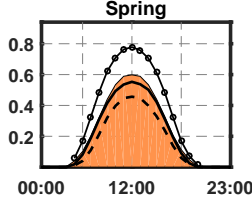

Summer

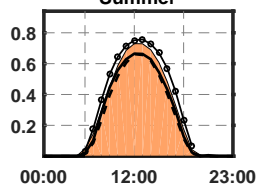

Summer

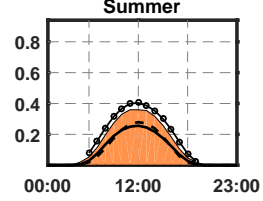

Summer

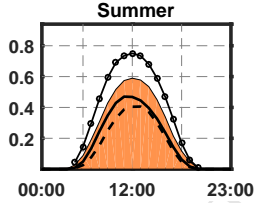

Autumn

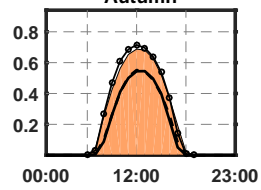

Autumn

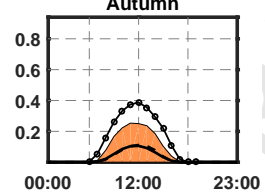

Autumn

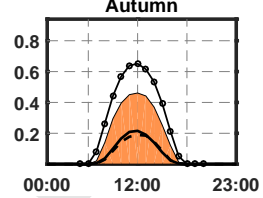

Figure 6: Solar power seasonal daily average production in Murcia, Spain (top row), Bremen and Lower Saxony, Germany (middle row) and Liege, Belgium (bottom row). The full and dashed lines represent the historical and simulated mean production. The dotted line and shaded orange area represent the historical and simulated $95^{t h}$ percentile respectively

were available regarding the inclination and orientation of the panels inside each area, the scenario approach closely matched the daily profile, proving the value of the proposed methodology. PV generation presents a strong daily deterministic structure due to the Earth's rotational movement. Hence, analysing the temporal variations of the data can provide a better picture of their temporal structure than autocorrelation functions. Figure 7 illustrates the variation of aggregated solar power per country for different time scales. The results are presented as a per unit of the installed capacity in the region. Table 4 summarizes some basic statistics of the model outputs: mean, standard deviation (SD), minimum (min), maximum ( $\max$ ), mean absolute error (MAE), adjusted coefficient of variation $R^{2}$ and correlation coefficient $\rho$. All the statistics are presented in terms of capacity factors i.e. as a percentage of the installed capacity, except for $R^{2}$ and $\rho$ which are dimensionless and measure the strength of the linear dependence between measured and simulated series, where 100 correspond to perfect linear dependence. Simulated results are presented between 

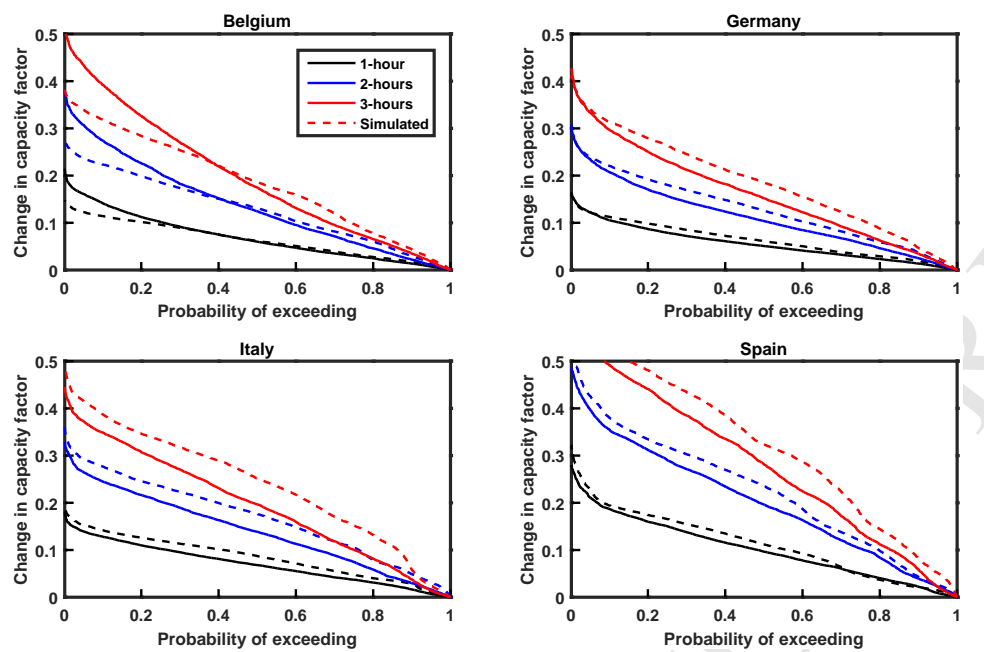

Figure 7: Fluctuations of measured and simulated solar power capacity factor for different time scales. Full lines represent measurements whilst dashed lines correspond to simulated data.

parenthesis.

Table 4: Summary statistics for the validation year

\begin{tabular}{|c|c|c|c|c|c|c|c|}
\hline & Mean (\%) & $\mathrm{SD}(\%)$ & Min (\%) & $\operatorname{Max}(\%)$ & $\operatorname{MAE}(\%)$ & $R^{2}$ & $\rho$ \\
\hline \multicolumn{8}{|c|}{ Solar Power } \\
\hline Belgium & $11.8(11.2)$ & $18.8(16.4)$ & $0(0)$ & $80.4(60.0)$ & 4.5 & 81.8 & 90.5 \\
\hline Germany & $10.0(11.2)$ & $15.2(16.2)$ & $0(0)$ & $67.2(59.8)$ & 2.8 & 89.8 & 94.8 \\
\hline Italy & $12.6(15.0)$ & $17.6(20.2)$ & $0(0)$ & $61.4(69.4)$ & 3.7 & 91.7 & 95.8 \\
\hline Spain & $20.2(20.0)$ & $26.1(27.2)$ & $0(0)$ & $84.5(87.5)$ & 6.9 & 92.6 & 96.3 \\
\hline \multicolumn{8}{|c|}{ Wind power } \\
\hline Belgium & $24.2(30.1)$ & $22.3(27.3)$ & $0(0)$ & $91.2(95.0)$ & 9.6 & 81.1 & 90.1 \\
\hline Germany & $15.2(17.2)$ & $14.3(16.6)$ & $0(0)$ & $78.7(87.3)$ & 4.5 & 86.6 & 93.1 \\
\hline Italy & $19.2(18.6)$ & $14.6(16.7)$ & $0.3(0.2)$ & $72.5(88.7)$ & 6.6 & 70.1 & 83.8 \\
\hline Spain & $23.7(23.9)$ & $14.0(15.2)$ & $0.6(0.6)$ & $74.8(81.8)$ & 4.6 & 84.7 & 92.1 \\
\hline
\end{tabular}




\subsection{Advantages of the model}

The orientation and inclination of the PV panels have a significant influence on the shape of the PV generation profile during the day. In large geographical

south orientation, $30^{\circ}$ tilt. In Germany, the aggregated PV curve approach clearly improved the single scenario assumption, specially during the second 

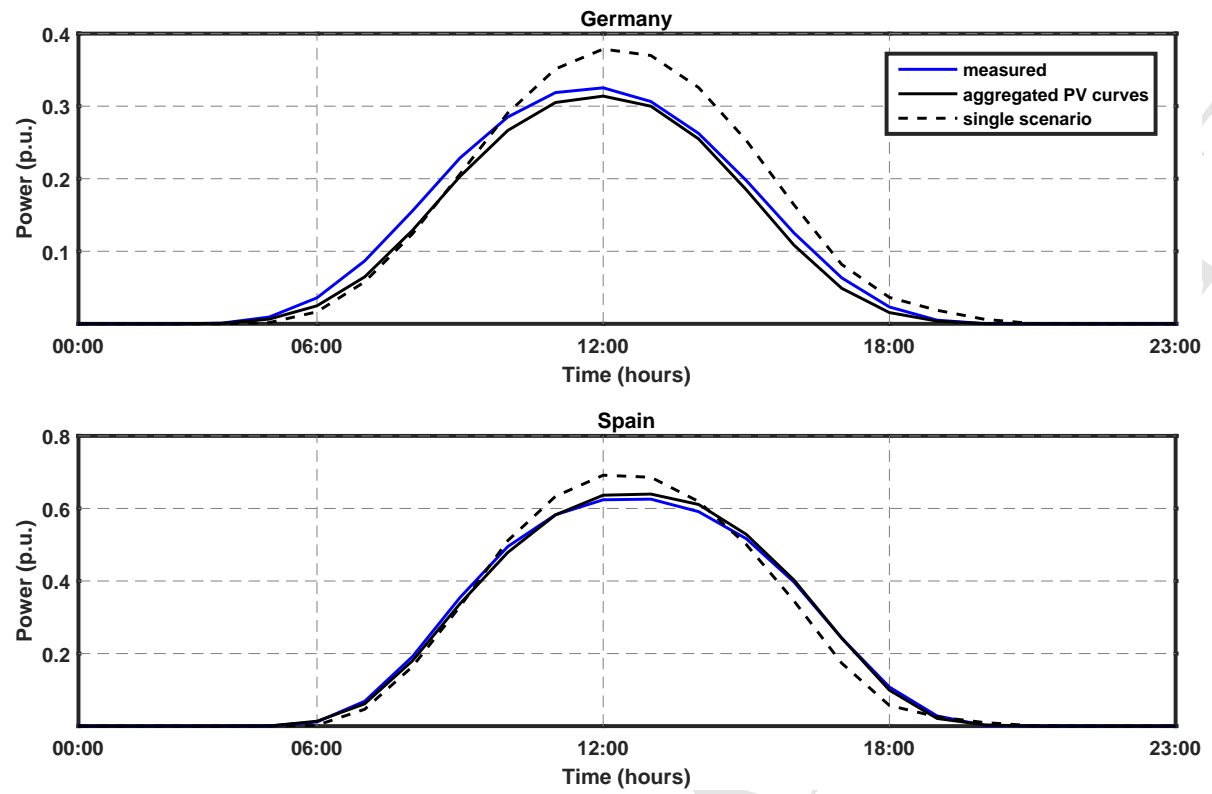

Figure 8: Daily average profile of PV generation for the validation year. Measured data is presented in blue, simulated data using the aggregated PV power curves is depicted in black and the simulated data assuming south orientation and 30 degrees inclination inside the area is drawn in dashed black lines.

half of the day. The proposed method also improved the accuracy of the simulations in Spain, although the difference was much smaller. This indicated that the single scenario assumption was indeed a good initial approximation of the average inclination and orientation of the panels in the area as shown in Table 3 However, as previously shown, this assumption might not hold for various locations. Differences in the daily profile might not necessarily impact the total capacity factor e.g. the same generation might just be slightly shifted in time. Nonetheless, they can be extremely relevant for different applications such as the calculation of the net demand of the system, for which wind and solar generation need to be combined with the electrical consumption.

\subsection{Simulation results}

The meteorological and power conversion models presented in Sections 2 and 3 respectively can be used to perform large-scale simulations. Since the use 
of empirical power curves (see Figure 3) was limited to the regions for which data were available, we assumed a single power curve for countries with similar weather characteristics, as illustrated in Figure 9. The differences in the slopes relate to the availability of the solar resource as well as the distribution of inclination and orientation angles of the panels across the area. For instance, for the same effective irradiance level, the panels located in Spain will produce less normalized power than those situated in Belgium or Germany, just due to the fact that they generally receive much more irradiation over the year. Therefore, the maximum theoretical production would be reached at an average effective irradiance higher than $1,000 \mathrm{~W} / \mathrm{m}^{2}$. Considering that the solar radiation in Italy resembles the one found in Spain, the differences in the power curves might be due to the internal geographical distribution of the panels. In this specific case, the installed capacity in Italy is approximately 3.5 times higher than in Spain and the panels are smaller and more evenly distributed across the whole country. This fact increases the aggregated efficiency e.g. the maximum pro-

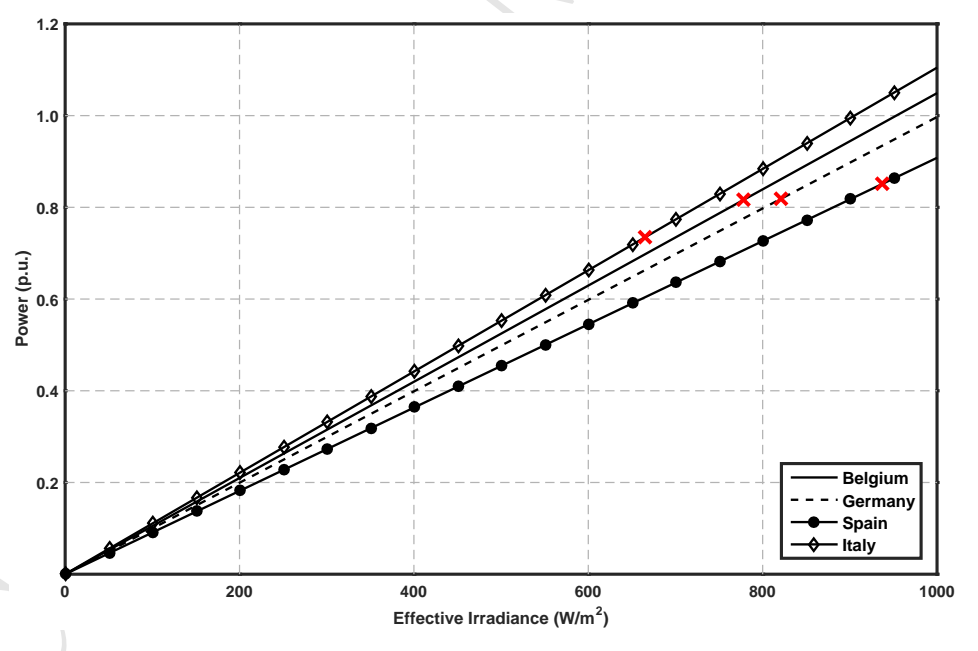

Figure 9: Aggregated power curves for different European countries

duction is achieved at a much lower mean effective irradiance. In practice, not all the PV generation capacity will be fully utilized instantaneously; hence the measured historical maxima during the calibration set are represented by red 
marks in Figure 9. The results in terms of capacity factors of a wind and solar scenario year for Europe are presented in Figure 10. As expected, wind and solar potentials are unevenly distributed across the continent. North European countries present generally larger wind capacity factors due to excellent quality of the wind resource. However, there are some specific results that may seem counter-intuitive at first and hence require some clarification. Specific countries e.g. Slovakia, Croatia or Macedonia presented significantly large capacity factors. This fact, nonetheless, is related to the current level of wind power
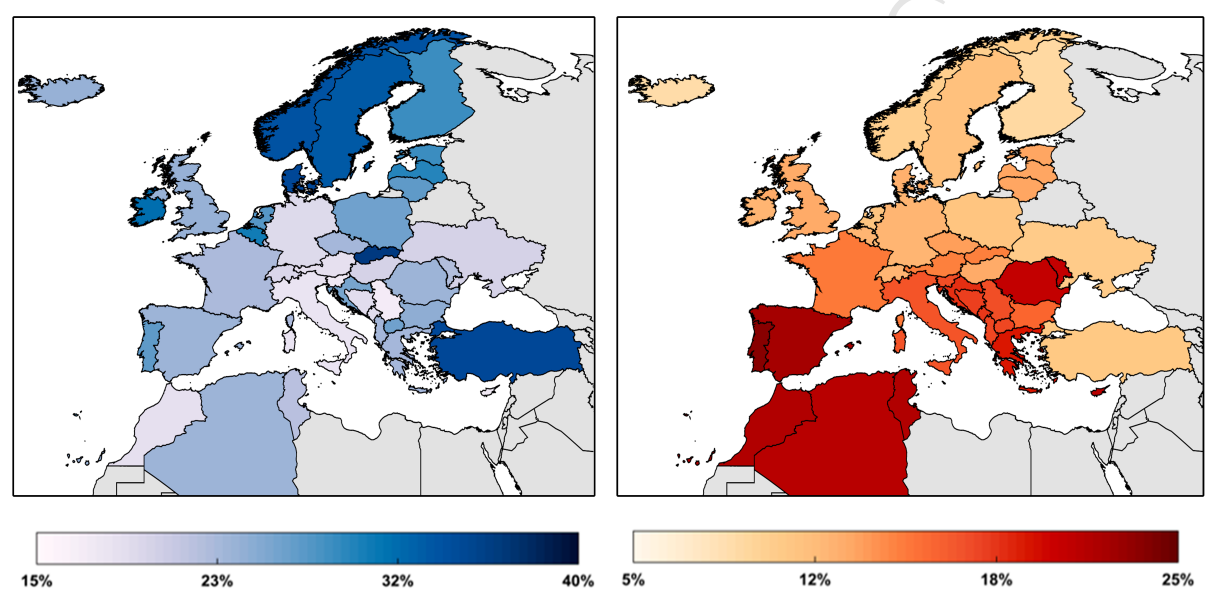

Figure 10: Annual simulated capacity factors for different European countries in 2015 for wind generation (left) and PV power production (right)

development in those regions rather than to the wind resource in itself. Under an early-stage wind power deployment, the installed capacity tends to be concentrated within a few wind farms, generally placed in areas with favourable wind resource. Therefore, the total capacity factor will be greater compared to those in which the wind fleet is spread over a large area. For example, northern Germany shows a exceptional wind potential, although having a much larger installed capacity spread across other locations across the country lowers its total wind capacity factor. With respect to solar generation, south European and north African countries showed significantly higher solar capacity factors due to a better yearly irradiation. Similarly to wind, solar capacity factors 
should be seen as a measure of efficiency rather than a measure of the total generated power. For example, even though the solar PV installed capacity in Germany is approximately ten times higher than in Spain, its solar capacity factor is much smaller due to the poorer meteorological resource available. In

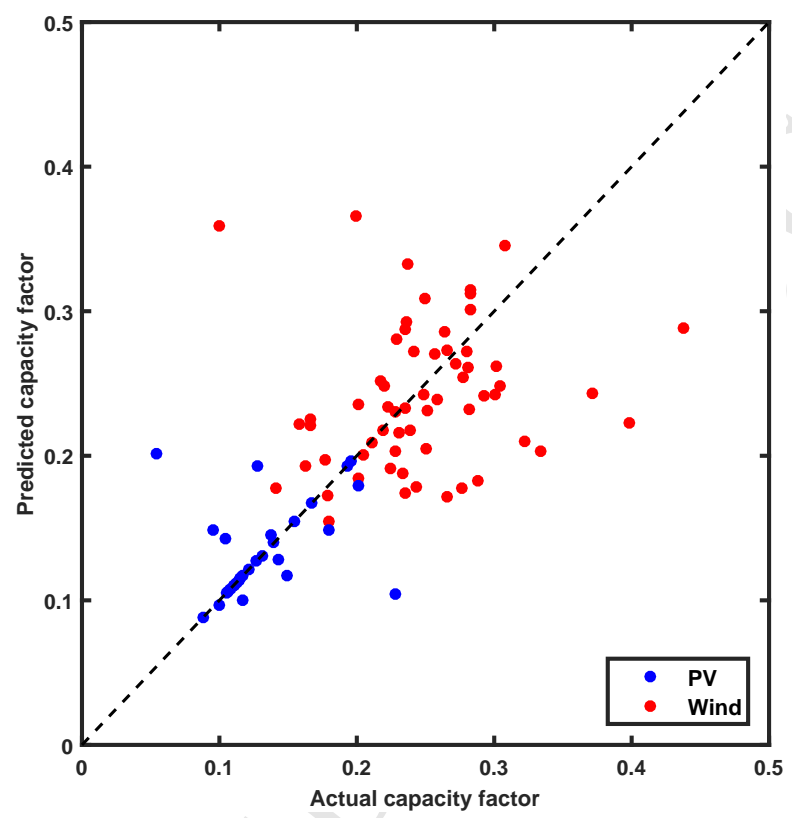

Figure 11: Errors in simulated PV and wind capacity factors for the calibration year

order to validate the model spatially, Figure 11 presents the errors in the simulated capacity factors for the calibration year, based on annual production and installed capacities reported by eurostat. Wind capacity factors were matched very well. On the other hand, solar capacity factors showed a higher dispersion, due to the uncertainty associated to the data i.e. PV locations, inclinations and orientations. Nonetheless, the model proved to performed quite accurately. These results can also be used to reproduce the long-term inter annual variability in renewable generation. As an example, Figure 12 shows the box plots of the simulated monthly capacity factor in Ireland and Hungary using 30 years of meteorological information (1985-2015). In both cases, there is a clear yearly profile leading to higher wind production during winter months. However, there 

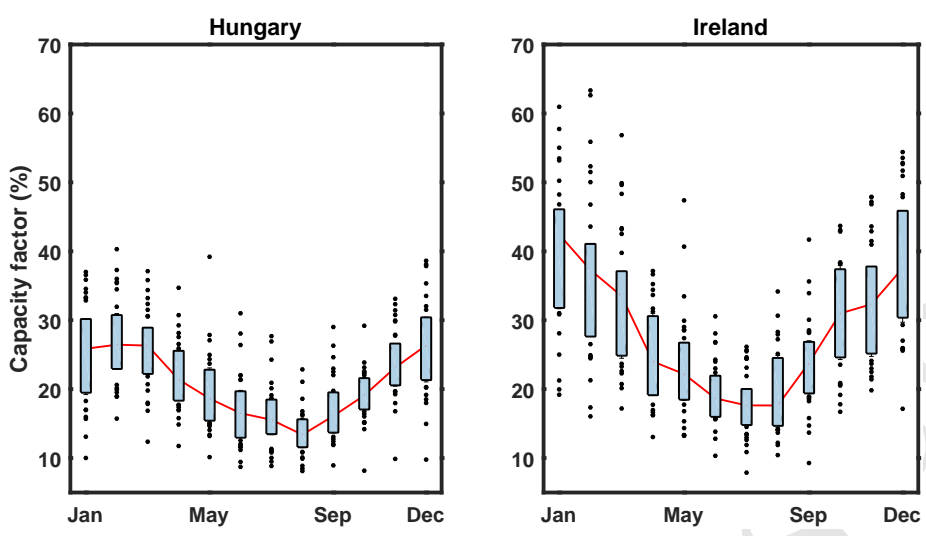

Figure 12: Distribution of the monthly capacity factor in two European countries based on 30 years of simulations

is a significant difference between the wind resource in both countries, which translates not only into a much higher potential production in Ireland, but also a much higher monthly and inter-annual variability.

\section{Conclusion}

Wind and power generators are expected to play a dominant role in modern power systems; however, their dependence on weather represents a fundamental difference compared to the conventional power generation methods. Therefore, there is a need to develop models to capture their variability at different geographical and temporal scales. In this paper, we addressed the problem of simulating wind and solar generation over large transcontinental areas. We based our analyses on meteorological reanalysis techniques using the Weather Research and Forecasting (WRF) model. Subsequently, we obtained the power production via aggregated power curves; mapping the meteorological variables to electrical power. They represent a well-known technique in wind power modelling, however, the limited information and uncertainties associated to large-scale solar generation e.g. location, orientation and inclination of the panels, called for a more specific methodology. We proposed a performance model approach, which required the definition of a reference panel for each area with a fixed optimal 
orientation and inclination matching historical PV series. We considered various scenarios, each corresponding to a single combination of orientation and inclination angles for all the panels inside a given area. Subsequently, we obtained a weight for each individual scenario in order to minimize the difference with respect to the measured annual capacity factor. These weights allow calculating the effective irradiance over an area which can be then used to define a linear aggregated power curve. We validated the simulated time series using one year of actual power measurements, focusing on the average daily performance of the model in different seasons for different climatic areas. The results showed a close match of the average daily profile, although in some cases the model overestimated the extreme events, represented by the $95^{\text {th }}$ percentile of the data. These discrepancies can be explained through the fact that our model reproduces the total available power, which might sometimes not be fully utilized due to network congestion or each individual TSO policies. Furthermore, we illustrated how the proposed methodology can be used to generate annual capacity factor maps over large continental regions covering different climatic areas as well as to capture both inter-annual and intra-annual variability of renewable generation. We believe that this information can serve to significantly improve network development plans, adequacy and market and renewable integration studies, therefore facilitating the future transition towards a more sustainable power grid.

\section{Acknowledgement}

The research leading to these results has received funding from the European Union Seventh Framework Programme under Grant Agreement No. 608540 GARPUR project.

\section{References}

[1] H. Louie, Correlation and statistical characteristics of aggregate wind power in large transcontinental systems, Wind Energy 17 (6) (2014) 793-810. 
[2] A. Malvaldi, S. Weiss, D. Infield, J. Browell, P. Leahy, A. Foley, A spatial and temporal correlation analysis of aggregate wind power in an ideally interconnected Europe, Wind Energy (2017).

[3] J. Widén, Correlations between large-scale solar and wind power in a future scenario for Sweden, IEEE transactions on sustainable energy 2 (2) (2011) $177-184$.

[4] J. Olauson, M. Bergkvist, Modelling the swedish wind power production using MERRA reanalysis data, Renewable Energy 76 (2015) 717-725.

[5] L. C. Cradden, F. McDermott, L. Zubiate, C. Sweeney, M. O'Malley, A 34-year simulation of wind generation potential for ireland and the impact of large-scale atmospheric pressure patterns, Renewable Energy 106 (2017) $165-176$.

[6] D. Lingfors, J. Widén, Development and validation of a wide-area model of hourly aggregate solar power generation, Energy 102 (2016) 559-566.

[7] M. Marinelli, P. Maule, A. N. Hahmann, O. Gehrke, P. B. Nørgrd, N. A. Cutululis, Wind and photovoltaic large-scale regional models for hourly production evaluation, IEEE Transactions on Sustainable Energy 6 (3) (2015) 916-923.

[8] A. N. Hahmann, D. Rostkier-Edelstein, T. T. Warner, F. Vandenberghe, Y. Liu, R. Babarsky, S. P. Swerdlin, A reanalysis system for the generation of mesoscale climatographies, Journal of Applied Meteorology and Climatology 49 (5) (2010) 954-972.

[9] A. N. Hahmann, C. L. Vincent, A. Peña, J. Lange, C. B. Hasager, Wind climate estimation using WRF model output: method and model sensitivities over the sea, International Journal of Climatology 35 (12) (2015) $3422-3439$.

[10] W. Skamarock, J. Klemp, J. Dudhia, D. Gill, D. Barker, M. Duda, X. Huang, W. Wang, J. Powers, A description of the advanced research 
WRF Version 3 Technical Note NCAR, TN-475+ STR National Center for Atmospheric Research Boulder (2008).

[11] A. N. Hahmann, C. Lennard, J. Badger, C. L. Vincent, M. C. Kelly, P. J. Volker, B. Argent, J. Refslund, Mesoscale modeling for the Wind Atlas of South Africa (WASA) project, DTU Wind Energy (0050 (updated)) (2014) 80, available from: http://orbit.dtu.dk/services/downloadRegister/ 107110172/DTU_Wind_Energy_E_0050.pdf (visited: 2017-03-07).

[12] D. Dee, S. Uppala, A. Simmons, P. Berrisford, P. Poli, S. Kobayashi, U. Andrae, M. Balmaseda, G. Balsamo, P. Bauer, et al., The ERA-Interim reanalysis: Configuration and performance of the data assimilation system, Quarterly Journal of the royal meteorological society 137 (656) (2011) 553597.

[13] R. W. Reynolds, N. A. Rayner, T. M. Smith, D. C. Stokes, W. Wang, An improved in situ and satellite SST analysis for climate, Journal of climate 15 (13) (2002) 1609-1625.

[14] G. L. Mellor, T. Yamada, Development of a turbulence closure model for geophysical fluid problems, Reviews of Geophysics 20 (4) (1982) 851-875.

[15] P. Jimenez, J. Hacker, J. Dudhia, S. E. Haupt, J. Ruiz-Arias, C. Gueymard, G. Thompson, T. Eidhammer, A. Deng, WRF-solar: An augmented nwp model for solar power prediction. Model description and clear sky assessment, Bulletin of the American Meteorological Society 12 (14) (2015) 2015.

[16] M. Litong-Palima, M. H. Bjerge, N. A. Cutululis, L. H. Hansen, P. Sørensen, Modeling of the dynamics of wind to power conversion including high wind speed behavior, Wind Energy (2015).

[17] N. A. Cutululis, M. Litong-Palima, L. Zeni, A. Gøttig, N. Detlefsen, P. E. Sørensen, Offshore wind power data: Deliverable no: 16.1, Tech. rep., 
available from: http://orbit.dtu.dk/files/60524700/0ffshore_wind_ power_data_final.pdf (visited: 2017-03-07) (2012).

[18] T. Huld, A. M. G. Amillo, Estimating PV module performance over large geographical regions: The role of irradiance, air temperature, wind speed and solar spectrum, Energies 8 (6) (2015) 5159-5181.

[19] E. Neau, Photovoltaic Energy: methods developed by RTE to facilitate integration of this production, in: 1st international Workshop on integration of solar power into Power Systems, Aarhus (Denmark), (2011).

[20] D. L. King, J. A. Kratochvil, W. E. Boyson, Photovoltaic array performance model, United States. Department of Energy, (2004).

[21] D. L. King, S. Gonzalez, G. M. Galbraith, W. E. Boyson, Performance model for grid-connected photovoltaic inverters, Sandia National Laboratories, Tech. Rep (2007).

[22] N. Eurostat, Nomenclature of territorial units for statistics NUTS 2010/EU-27 (2011). 


\section{Manuscript highlights}

- Sound methodology to generate large-scale renewable generation time series based on meteorological reanalysis data.

- Proposed a novel PV power conversion method based on aggregated power curves.

- Simulated 35 years of hourly wind and PV generation at the pan-European level.

- Results validated for different climatic areas using data from Transmission System Operators (TSOs). 